\title{
A scanning electron micrnscopy study of the effect of proteinase inhibitors on mouse uterine morphology
}

\author{
Sharon M. Noonan*, Danica Dabich $\dagger$, T. J. Andary $\dagger \ddagger$ and \\ W. C. Pitchford $\S$ \\ Departments of Pathology and $\nmid$ Biochemistry, Wayne State University School of Medicine, \\ Detroit, Michigan 48201, U.S.A.
}

\begin{abstract}
Summary. The luminal uterine surface of mice was examined by scanning electron microscopy after a $24 \mathrm{~h}$ treatment with basic pancreatic trypsin inhibitor (BPTI) or L-1-tosylamido-2-phenylethyl chloromethyl ketone (TPCK) administered as a single injection or from a slow release capsule on Day 2 p.c. in doses known to impair fertility. The effect of BPTI was slight, some swelling of cells and loss of microvilli. TPCK, on the other hand, caused disruption of the epithelium through swelling and sloughing of cells, sporadic loss of microvilli, and the presence of red blood cells.
\end{abstract}

\section{Introduction}

The antifertility effects of proteinase inhibitors have primarily been studied in relation to their effects on spermatozoa (Zaneveld, 1976). In vivo, however, these compounds may also modify the physiological activity of the egg, developing embryo, fluids of the reproductive tract and/or the reproductive tract itself (see Zaneveld, 1976; Denker, 1977, for reviews). In the present study endometrial surface modifications of mouse uteri were examined after treatment with two proteinase inhibitors known to impair fertility in this species (Dabich \& Andary, 1974). The inhibitors were basic pancreatic trypsin inhibitor (Kunitz \& Northrup, 1936), a naturally occurring substance, and L-1-tosylamido-2-phenylethyl chloromethyl ketone (Schoellmann \& Shaw, 1963), a synthetic inhibitor of chymotryptic-like enzymes.

\section{Materials and Methods}

\section{Solutions}

Basic pancreatic trypsin inhibitor (BPTI: Sigma, St. Louis, Missouri) was prepared in physiological saline $(9 \mathrm{~g} \mathrm{NaCl} / 1)$. L-1-Tosylamido-2-phenylethyl chloromethyl ketone (TPCK: Sigma) was dissolved in $95 \%$ ethanol. The concentration of both solutions was $3 \mathrm{~g}$ inhibitor/l solvent.

\section{Treatments of animals}

Female Swiss Webster mice, 8-12 weeks of age, were induced to superovulate (Brinster, 1967) and mated. The presence of a copulation plug on the day after injection of hCG was regarded as Day 1 post coitum (p.c.).

* Deceased.

$¥$ Present address: Hyland Laboratories, 3300 Hyland Avenue, Costa Mesa, California 92626, U.S.A.

$\S$ Present address: Department of Rheumatology, Henry Ford Hospital, Detroit, Michigan 48202, U.S.A. 
On Day 2 p.c., the animals were anaesthetized by intraperitoneal injection of $0.05 \mathrm{ml}$ sodium pentobarbitone $(60 \mathrm{mg} / \mathrm{ml})$. After exposure of the bicornuate uterus, saline or $95 \%$ ethanol was placed in one uterine horn (control) via injection or slow release capsule; the corresponding inhibitor solution was introduced similarly into the opposite horn. The treatment volumes were $50 \mu \mathrm{l}$ solvent or inhibitor solution by injection or $4 \mu \mathrm{l}$ by means of a slow release capsule prepared from Silastic tubing (Garrett \& Chemburkar, 1968). The quantity of inhibitor delivered by these routes was known from previous studies to impair fertility (Dabich \& Andary, 1974). The site of injection or capsule insertion was always within the ovarian third of the horn, thus limiting the area affected by manipulations and leaving the rest of the horn available for morphological evaluation of the treatment. In addition to the 4 experimental treatments (Group 1, BPTI released from a capsule; Group 2, BPTI injected; Group 3, TPCK from a capsule; Group 4, TPCK injected), some mice were left untreated (Group 5) so that the normal morphology of the pregnant mouse uterus could be examined in relation to the preparative technique. There were 4 mice in each group.

\section{Scanning electron microscopy}

The animals were killed approximately $24 \mathrm{~h}$ after drug treatment. A small amount of freshly prepared $0.6 \mathrm{M}$-cacodylate-buffered glutaraldehyde $(1 \% \mathrm{w} / \mathrm{v})$ was immediately and gently infused into each horn to fix the tissue as rapidly as possible. A single slit was then made

\section{PLATE 1}

Fig. 1. Saline-treated mouse uterus showing normal, undulating deep folds on the luminal surface.

Fig. 2. Higher magnification of Fig. 1 showing clearly delineated individual cells.

Fig. 3. Microvilli on epithelial cells of a saline-treated uterus are of various lengths and cover the entire cell surface.

Fig. 4. After ethanol treatment the microvilli appear shorter and collapsed.

\section{PLATE 2}

Fig. 5. The individual cells of the uterine epithelium after treatment with BPTI released from a capsule are enlarged and flattened.

Fig. 6. Flattening leads to the appearance of cell boundaries (arrows). The distribution and density of the microvilli are irregular, and some parts of the surface have no microvilli (X).

\section{PLATE 3}

Fig. 7. After injection of TPCK, there is disintegration and loss of epithelium in areas near the injection site.

Fig. 8. The presence of red blood cells $(*)$ corresponds with the macroscopically bloody appearance of the uteri after injection of TPCK.

\section{PLATE 4}

Figs 9-12. Mouse uteri after treatment with TPCK from a capsule.

Fig. 9. Part of the uterus showing a few remaining clusters of epithelial cells (arrows).

Fig. 10. The underlying stroma is exposed but the detaching epithelial cells appear to have normal microvilli.

Fig. 11. These epithelial cells have become detached as a sheet and rolled up (arrow).

Fig. 12. An epithelial cell (X) with some microvilli but a smooth peripheral surface. Some red blood cells are present $(*)$. 

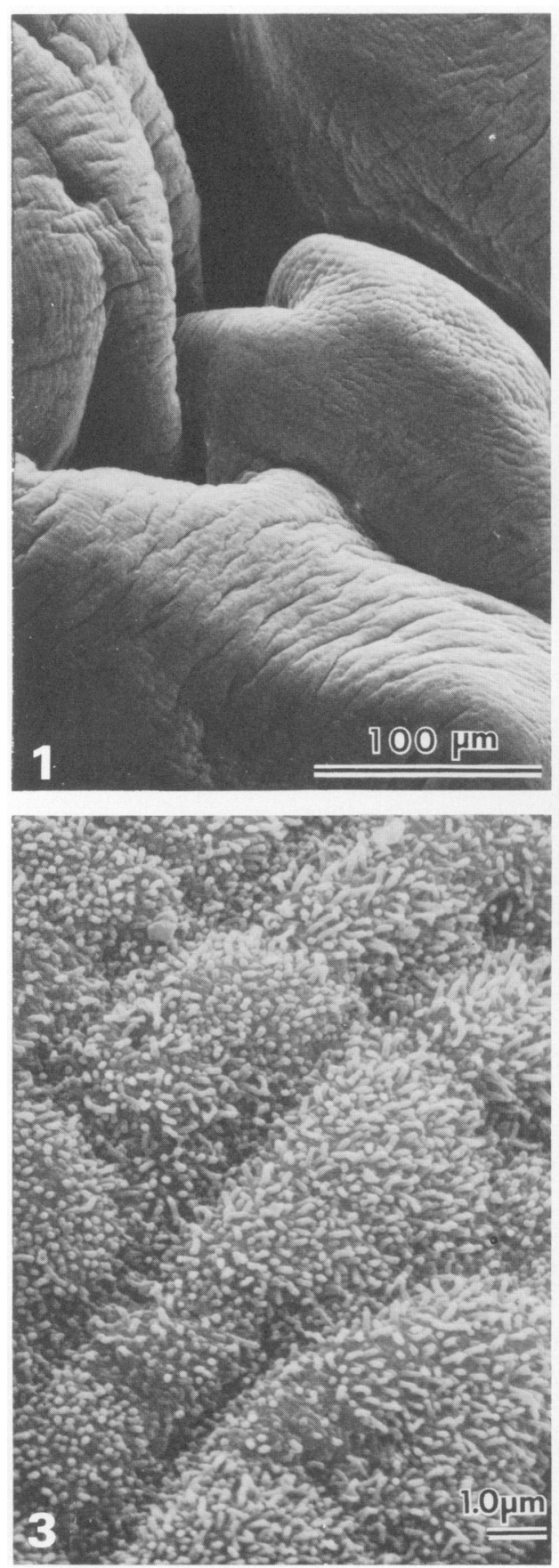
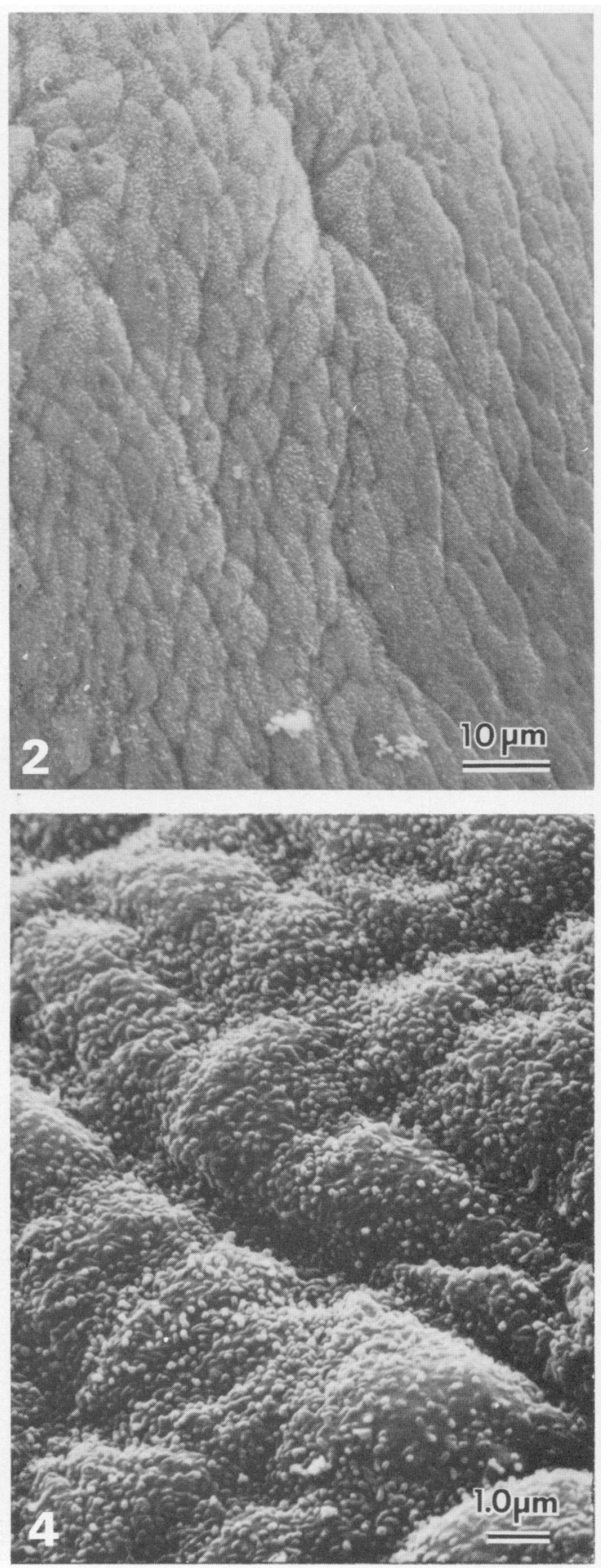
PLATE 2
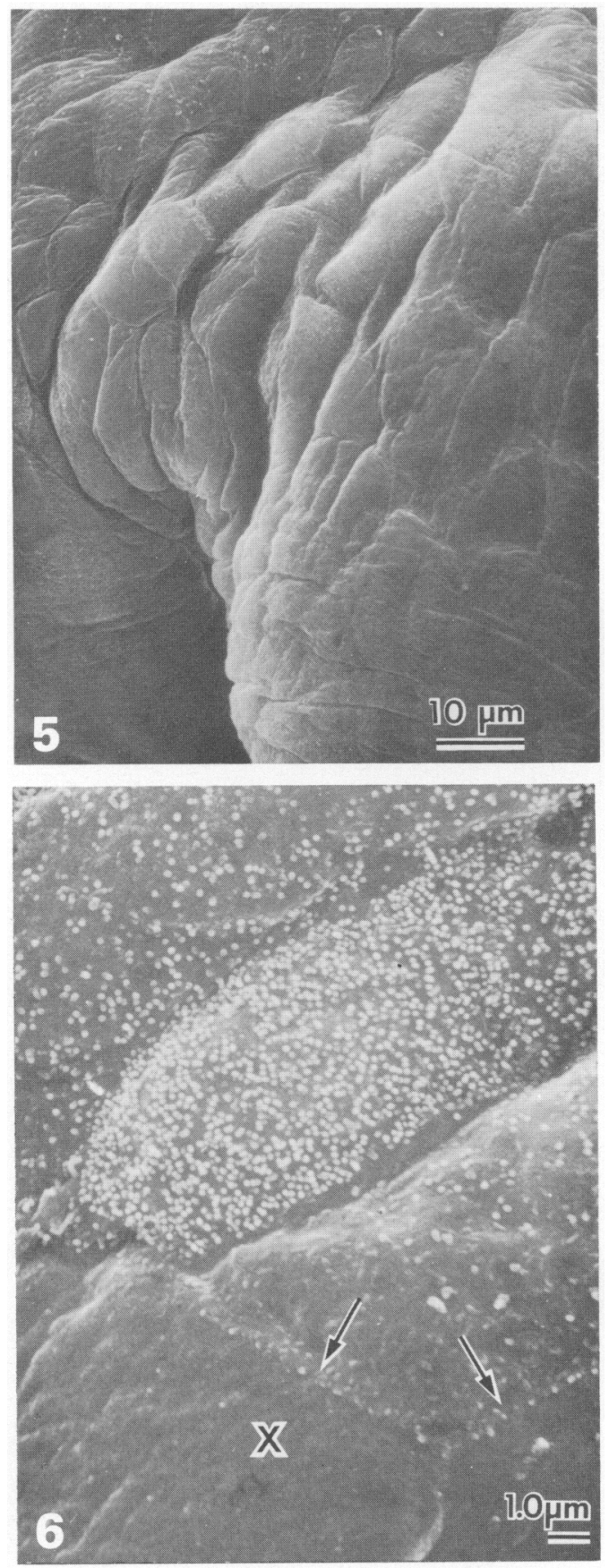
PLATE 3
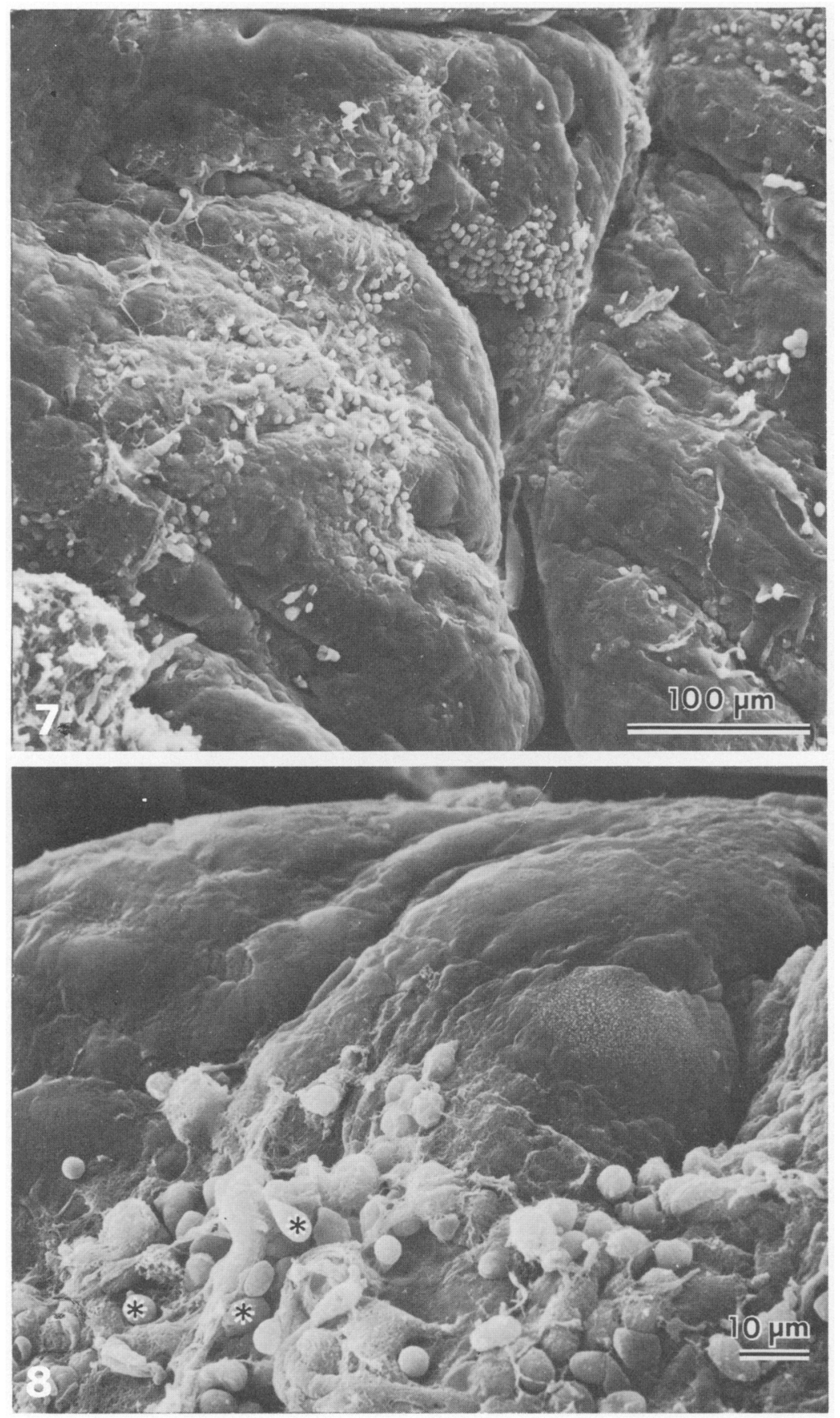

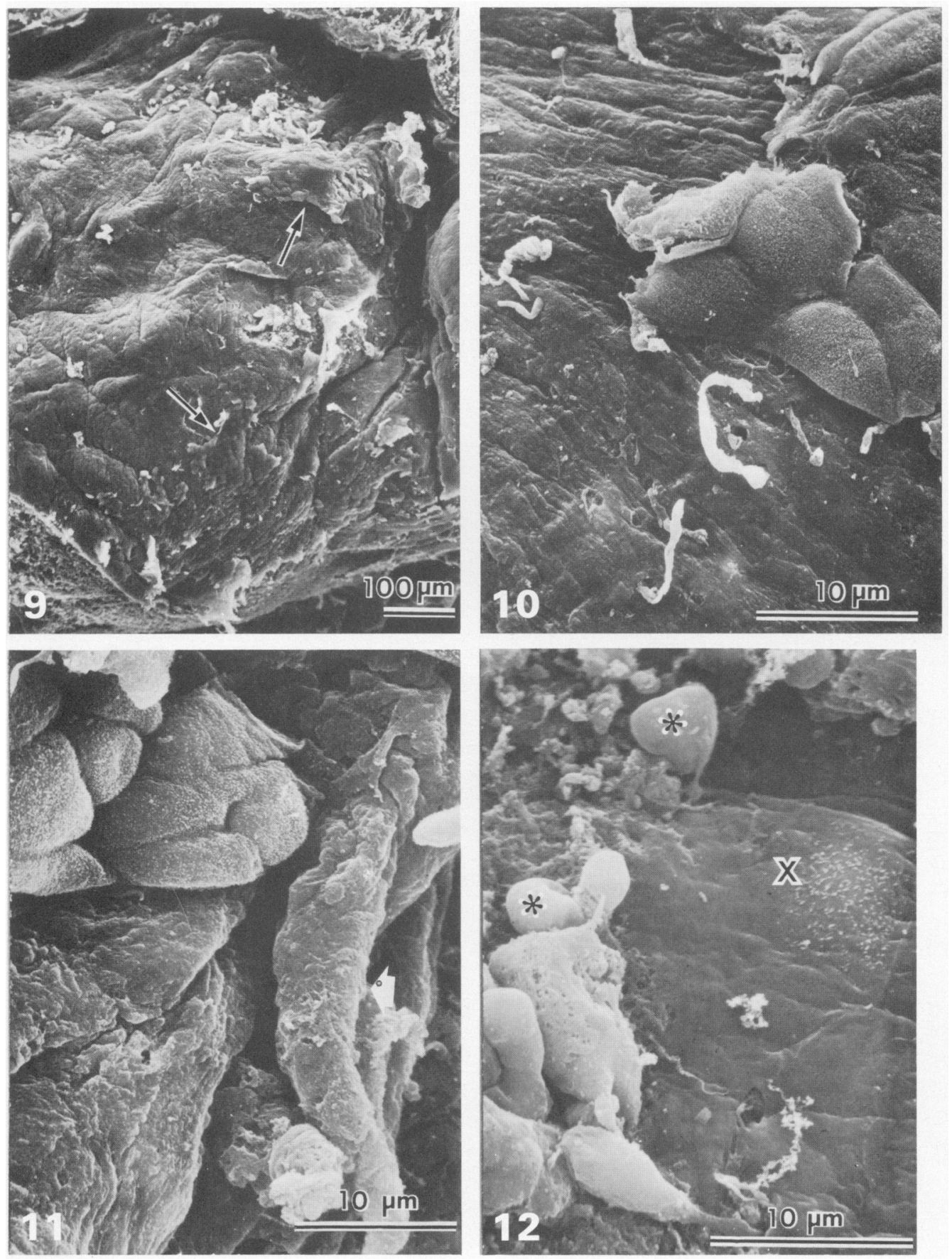
longitudinally while the specimen was immersed in the buffered glutaraldehyde solution. By using this technique, the luminal surfaces of both horns were exposed while the uterus was maintained as a single piece of tissue. This facilitated handling of the specimen and permitted immediate comparison of the drug-treated and solvent-treated horns. The uterine cavity was again gently flushed with glutaraldehyde to remove any mucus which would obscure the underlying surface morphology. Specimen fixation was continued in buffered glutaraldehyde for an additional $48 \mathrm{~h}$ at $4^{\circ} \mathrm{C}$. The tissues were then rinsed overnight in cacodylate-buffered sucrose $(0.2 \mathrm{M}), \mathrm{pH} 7 \cdot 2-7 \cdot 4$. After fixation, the samples were progressively dehydrated with ethanol and dried by a critical-point procedure using Freon-113 and the Parr bomb (Lewis \& Nemanic, 1973). The samples, glued onto stubs, were sputter-coated with gold and examined in an ETEC autoscan electron microscope equipped with a $150 \mu \mathrm{m}$ aperture and operated at an accelerating voltage of $20 \mathrm{kV}$.

\section{Results}

The following descriptions represent typical effects for each treatment. The observations were made 'blind' and were consistent within the groups.

\section{Control horns}

The surface features of the untreated control specimens and those treated with saline (BPTI solvent) by injection or capsule showed identical cellular topography (Pl. 1, Figs 1-3). The only perceptible difference after exposure to $95 \%$ ethanol was that the covering microvilli were shorter and irregular (Pl. 1, Fig. 4) and that some areas were devoid of microvilli.

\section{Treated horns}

Injection or slow release of BPTI into the uterine lumen caused modifications as shown in Plate 2. The results were the same for both routes of administration. With TPCK, however, approximately one-third of the uterine lumen next to the injection site showed disintegration and loss of epithelium (Pl. 3, Fig. 7). Remaining epithelial cells, whose cell boundaries were lost, were smooth and microvilli, when present, were short and distorted. Red blood cells were common (Pl. 3, Fig. 8). In contrast, the morphology of the uterine third nearest the cervix (i.e. away from the injection site) appeared normal. There was no cellular sloughing, and microvilli were present in normal numbers and shape.

When TPCK was released from a capsule, extensive loss of epithelium occurred and the entire uterine surface was modified by the inhibitor (Pl. 4, Fig. 9). Patches of debris and epithelial cell clusters composed of cells with a normal population of microvilli (Pl. 4, Fig. 10) or cells exhibiting various stages of cellular modification (smooth surfaced or swollen, with or without microvilli) were unevenly distributed on the underlying stroma (Pl. 4, Fig. 12). Rolled-up sheets of epithelial cells detached from underlying stroma, stromal elements and red blood cells were often seen (Pl. 4, Fig. 11).

\section{Discussion}

From the outlined morphological observations it appears that the cellular responses to and modes of action of TPCK and BPTI on mouse uterine tissue are different. Both compounds are classified as proteinase inhibitors on the basis of analyses with purified or cell-free preparations of proteolytic enzymes. In addition, TPCK, an active site-directed monofunctional alkylating 
agent, has also been used as an affinity agent or active site titrant for chymotrypsin and chymotrypsin-like enzymes (Shaw, 1975). The compound is not, however, active site specific. Chloromethyl ketones, the family of compounds to which TPCK belongs, can potentially alkylate a wide range of different molecules in living cells, e.g. any protein with available sulphydryl and/or imidazole groups, reduced glutathione, or nucleic acids (Ross, 1962; Chou, Black \& Roblin, 1974; Schnebli, 1975). The resulting covalent modifications could lead to perturbations in cellular integrity, function and association. This may account for the extensive morphological modifications induced by TPCK in contrast to BPTI. The only known function of BPTI, a polypeptide, is inhibition of certain serine proteinases by means of formation of enzyme-inhibitor complexes (Kassell, 1970; Ladzunski, Vincent, Schweitz, Peron-Renner \& Pudles, 1974; Barrett, 1977). Cellular functions affected by BPTI are, therefore, likely to be more limited within the $24 \mathrm{~h}$ period of drug exposure of these experiments.

The swelling of cells near sites of TPCK injection indicates impaired plasma membrane integrity and function. With sustained TPCK release, the drug appears to act on and disrupt cellular junctions between the uterine epithelium and underlying stroma, a process leading to formation of sheets of detached epithelial cells. Such morphological changes could account for the loss of fertility in mice treated with TPCK (Dabich \& Andary, 1974).

Cell detachment was not seen with BPTI. Since ethanol control treatment does not affect fertility, but treatment with BPTI does, the slight morphological changes induced by BPTI may not be the primary reason for the impairment. Effects on the functional integrity of uterine epithelial cells could, however, lead to alterations of uterine secretions which are known to affect the zygote (McLaren, 1970; Pinsker \& Mintz, 1973; Pinsker, Sacco \& Mintz, 1974; Hoversland $\&$ Weitlauf, 1978).

This project was supported in part by a grant from NICHD: HD-06234 and the Detroit General Hospital Research Corporation.

\section{References}

Barrett, A.J. (1977) Introduction to the history and classification of tissue proteinases. In Proteinases in Mammalian Cells and Tissues, pp. 1-55. Ed. A. J. Barrett. North-Holland, Amsterdam.

Brinster, R.L. (1967) Protein content of the mouse embryo during the first five days of development. $J$. Reprod. Fert. 13, 413-420.

Chou, I.M., Black, P.H. \& Roblin, R.D. (1974) Nonselective inhibition of transformed cell growth by a protease inhibitor. Proc. natn. Acad. Sci. U.S.A. 71, 1948-1952.

Dabich, D. \& Andary, T.J. (1974) Prevention of blastocyst implantation in mice with proteinase inhibitors. Fert. Steril. 25, 954-957.

Denker, H.W. (1977) Implantation. The role of proteinases and the blockage of implantation by proteinase inhibitor. Adv. Anat., Embryol. Cell Biol. 53, 5-120.

Garrett, E.R. \& Chemburkar, P.B. (1968) Evaluation, control and prediction of drug diffusion through polymeric membranes. II. J. Pharm. Sci. 57, 947959.

Hoversland, R.C. \& Weitlauf, H.M. (1978) The effect of estrogen and progesterone on the level of amidase activity in fluid flushed from the uteri of ovariectomized mice. Biol. Reprod. 19, 908-912.

Kassell, B. (1970) Bovine trypsin-kallikrein inhibitor
(Kunitz inhibitor, basic pancreatic trypsin inhibitor, polyvalent inhibitor from bovine organs). In Methods in Enzymology, Vol. XIX, pp. 844-852. Eds G. E. Perlmann \& L. Lorand. Academic Press, New York.

Kunitz, M. \& Northrup, J.H. (1936) Isolation from beef pancreas of crystalline trypsinogen, trypsin, a trypsin inhibitor, and an inhibitor-trypsin compound. J. gen. Physiol. 19, 991-1007.

Ladzunski, M., Vincent, J.P., Schweitz, H., PeronRenner, M., \& Pudles, J. (1974) The mechanism of association of trypsin (or chymotrypsin) with the pancreatic trypsin inhibitors (Kunitz and Kazal). Kinetics and thermodynamics of the interaction. In Proteinase Inhibitors, pp. 420-431. Eds H. Fritz, H. Tscheschi, L. J. Greene \& E. Truscheit. SpringerVerlag, New York.

Lewis, E.R. \& Nemanic, M.K. (1973) Critical point drying techniques. In Scanning Electron Microscopy, pp. 767-774. Eds O. Johari \& I. Corvin. IIT Research Inst., Chicago.

McLaren, A. (1970) The fate of the zona pellucida in mice. J. Embryol. exp. Morph. 233, 1-19.

Pinsker, M.C. \& Mintz, B. (1973) Changes in cellsurface glycoproteins of mouse embryos before implantation. Proc. natn. Acad. Sci. U.S.A. 70, 1645-1648. 
Pinsker, M.C., Sacco, A.B. \& Mintz, B. (1974) Implantation associated proteinase in mouse uterine fluid. Devl Biol. 38, 285-290.

Ross, W.C.J. (1962) Biological Alkylating Agents, pp. 32-50. Butterworth, London.

Schnebli, H.P. (1975) The effects of protease inhibitors on cells in vitro. In Proteinases and Biological Control, pp. 785-794. Eds E. Reich, D. B. Rifkin \& E. Shaw. Cold Spring Harbor, New York.

Schoellmann, G. \& Shaw, E. (1963) Direct evidence for the presence of histidine in active center of chymotrypsin. Biochemistry, N.Y. 2, 252-255.

Shaw, E. (1975) Synthetic protease inhibitors acting by affinity labeling. In Proteinases and Biological Control, pp. 455-465. Eds E. Reich, D. B. Rifkin \& E. Shaw. Cold Spring Harbor, New York.

Zaneveld, L.J.D. (1976) Sperm enzyme inhibitors as antifertility agents. In Human Semen and Fertility Regulation in Man, ch. 56, pp. 570-588. Ed. E. S. E. Hafez. C.V. Mosby, St. Louis.

Received 7 January 1980 